\title{
Sequential effects in time perception
}

\author{
TAMSEn E. TAYLOR AND STEPhen J. LUPKER \\ University of Western Ontario, London, Ontario, Canada
}

\begin{abstract}
Taylor and Lupker (2001) reported that in a naming task, stimuli were named more rapidly when preceded by an easy-to-name stimulus than when preceded by a difficult-to-name stimulus (sequential effects). The goal of the present research was to investigate whether sequential effects could be explained in terms of time perception processes (within the context of Lupker, Brown, and Colombo's [1997] time criterion account). Participants were required to name easy and difficult stimuli (high-frequency words and nonwords in Experiment 1; words only in Experiment 2). Each naming trial was followed by a set of asterisks $(* * * * *)$. The participants were required to press a button when they thought the asterisks had been presented for exactly $1 \mathrm{sec}$. Time intervals produced after naming difficult stimuli were longer than time intervals produced after naming easy stimuli. That is, time perception was affected by the difficulty of word/nonword naming in a way that carried over to the next stimulus, supporting the idea that carryover effects in time perception may be the source of sequential effects in the naming task.
\end{abstract}

Taylor and Lupker (2001) reported a pattern of results in a naming task that they referred to as sequential effects. Specifically, when randomly mixed sets of easy and difficult stimuli were named, latencies were $8-17 \mathrm{msec}$ shorter following an easy-to-name stimulus than following a difficult-to-name stimulus. Crucially, this pattern was essentially independent of the nature of the stimuli being named, since the pattern arose when high-frequency consistent words were mixed with nonwords, when highand low-frequency inconsistent words were mixed, and when easy and hard nonwords were mixed.

The fact that sequential effects were a function only of stimulus difficulty, and not of the qualitative nature of the stimuli (e.g., words vs. nonwords), led Taylor and Lupker (2001) to conclude that their effects were not due to trial-to-trial shifts in the way the stimuli were named. In particular, they concluded that their sequential effects were not due to a shifting of route emphasis within a dualroute framework (e.g., Coltheart, Rastle, Perry, Langdon, $\&$ Ziegler, 2001). The idea that readers have the ability to shift route emphasis has received considerable attention recently (e.g., Monsell, Patterson, Graham, Hughes, \& Milroy, 1992; Zevin \& Balota, 2000). The specific suggestion is that readers can facilitate performance by strategically altering route emphasis in anticipation of particular stimulus types (e.g., nonwords). There would then be a cost if the subsequent stimulus was a different type (e.g., a word). If readers were making changes of this sort in Taylor and Lupker's (2001) experiments, the expectation is that sequential effects would have been dependent on the nature of the stimuli named on adjacent trials, in contrast to the independence that Taylor and Lupker (2001) observed.
Taylor and Lupker (2001) interpreted their results as being due to readers' use of a time criterion (Chateau \& Lupker, 2003; Kinoshita \& Lupker, 2002, 2003; Lupker, Brown, \& Colombo, 1997) when naming letter strings. According to the time criterion account, readers establish a point in time at which they expect to respond (their criterion placement) and then try to respond when that time criterion is reached. Taylor and Lupker (2001) suggested two ways in which sequential effects could arise within this framework. One way is that participants adjust the position of their time criterion on a trial-by-trial basis depending on the ease of naming the most recent stimulus. For example, following an easy item, the criterion might be adjusted to a more strict position, resulting in a faster response on the next trial. A second way is that there may be changes in how participants perceive the passage of time, with stimulus difficulty on one trial affecting time perception on the next trial. For example, perceived time may pass more quickly after an easy item is responded to. Thus, the criterion would be reached sooner on the next trial, producing a faster response.

Recently, Taylor and Lupker (2006) provided evidence supporting the idea that time perception processes can play a role in speeded response tasks. In Taylor and Lupker's (2006) experiments, participants were asked to name stimuli but to delay their naming responses until the presented stimulus had been on the computer screen for exactly $1 \mathrm{sec}$. The standard stimulus difficulty effects seen in speeded naming (i.e., frequency, lexicality) also appeared in this internal-timing task.

Taylor and Lupker's (2006) explanation for these results is based on the idea that if participants are using a time criterion, they must monitor the passage of time in order to

S. J. Lupker, lupker@uwo.ca 
know when the criterion has been reached. Hence, any impact of stimulus difficulty on time perception should show up in any task in which responding is based on timing operations (i.e., according to the time criterion account, in all speeded response tasks). In fact, the time perception literature contains considerable evidence that people's time perception processes are affected by the difficulty of the stimuli being processed and that the direction of these effects is consistent with Taylor and Lupker's (2006) recent results. For example, Warm and McCray (1969) presented words that varied in frequency and length for exactly $1 \mathrm{sec}$. The participants were asked to estimate the duration of the stimuli. Warm and McCray observed significant effects of word frequency and length on duration estimations, with participants perceiving easier words (highfrequency and short words) as being presented for a longer time than were more difficult words (low-frequency and long words), even though all the words were presented for $1 \mathrm{sec}$. Thus, time appears to pass more quickly when easy stimuli are processed. Similar results have been reported by Chastain and Ferraro (1997) and Hochhaus, Swanson, and Carter (1991), also using words as stimuli, as well as by a number of researchers using other tasks and stimuli (e.g., Brown, 1985; Brown, Stubbs, \& West, 1992; Casini \& Macar, 1997; Fortin, Rousseau, Bourque, \& Kirouac, 1993; Hicks, Miller, \& Kinsbourne, 1976; McClain, 1983; Thomas \& Weaver, 1975).

If stimulus difficulty does influence time perception in the way indicated by these findings and if a time criterion does control responding in speeded tasks, the implication is that time perception processes are likely playing some role in those tasks. The present research was an attempt to determine whether time perception processes might also play a role in producing the sequential effects observed by Taylor and Lupker (2001) or whether the sequential effects have a different cause, such as trial-by-trial adjustments of the time criterion.

\section{EXPERIMENT 1}

In both experiments, the participants were required to perform two alternating tasks. First, they named a presented stimulus. After an intertrial interval, they attempted to produce a 1-sec interval (by pressing a button) in response to a string of asterisks. The timing stimulus (the string of asterisks) was identical on all the trials. Therefore, any difference in the produced timing intervals would presumably have to be due to carryover effects from the preceding (naming) trial. If the sequential effects observed by Taylor and Lupker (2001) were due to changes in time perception, carryover effects in time perception should be observed. The participants in Experiment 1 should produce shorter time intervals after naming an easy stimulus (a high-frequency word) than after naming a difficult stimulus (a nonword) (i.e., time would seem to pass more rapidly after an easy stimulus had been named). In contrast, if sequential effects are due to changing the position of the time criterion for naming on a trial-by-trial basis, no carryover effects onto timing trials would be expected, because the participants should be using different criteria for the two types of trials. That is, they would be using a criterion designed to time a $1-\mathrm{sec}$ interval on timing trials and a criterion that maximizes speeded-naming performance on naming trials.

\section{Method}

Participants. Fifty-three undergraduate students received course credit in an introductory psychology course for their participation in this experiment. The participants reported having normal or corrected-to-normal vision and being native speakers of English.

Apparatus. The stimuli were presented on an IBM clone computer system (Trillium Computer Resources Model 316S-80MS), with a TTX Multiscan Monitor (Model 3435P). Both a microphone and a button box were used to record responses. The experimenter was present to record naming errors.

Stimuli. The easy stimuli were 30 high-frequency words (mean frequency $=122.271$; HAL norms from elexicon database, Balota et al., 2002). The difficult stimuli were 30 pronounceable nonwords (stimuli available at psychonomic.org/archive; see archived materials for Taylor \& Lupker, 2006). The stimuli were presented in a different random order for each participant. The participants received six practice trials, and these practice trials were always presented in the same order.

Procedure. The participants were tested individually. They were told that two types of trials would be presented in a strictly alternating fashion. First, they would be presented with a letter string, which they were to read aloud as quickly and as accurately as possible. Following each naming trial, a row of asterisks (*****) would appear on the computer screen. They should press a key on the button box when they thought that the asterisks had been on the screen for exactly 1 sec.

An attempt was made to constrain timing responses to a reasonable approximation of $1 \mathrm{sec}$ by presenting a high-pitched warning tone when responses were faster than $500 \mathrm{msec}$ and presenting a lower pitched warning tone when responses were slower than $1,500 \mathrm{msec}$. The participants were instructed to use the tones as feedback and to adjust their timing performance appropriately. Next, the six practice trials were presented. The experimental trials followed.

Initially, a fixation cross appeared in the middle of the screen, remaining until the experiment was complete. The stimuli were presented centered above the cross and remained until the letter string was named or the button box registered a timing response. Naming and timing trials strictly alternated. There was a 2-sec interval between the participant's response and an auditory cue indicating that the next trial was about to begin. The stimulus was presented $1 \mathrm{sec}$ after the cue (for a total intertrial interval of 3,000 msec). An auditory cue was employed because it had also been used in the sequential effects experiments reported in Taylor and Lupker (2001).

\section{Results}

Data trimming. Trials on which naming responses were incorrect were eliminated from the latency analyses ( $2.6 \%$ of the word trials and $8.2 \%$ of the nonword trials). A trial was considered an outlier and omitted from the latency analyses if the naming latency was less than $150 \mathrm{msec}$ or greater than $1,500 \mathrm{msec}$ (no trials had latencies that were less than $150 \mathrm{msec} ; 0.1 \%$ of the high-frequency word trials and $0.9 \%$ of the nonword trials had latencies that were greater than $1,500 \mathrm{msec})$. Timing trials were considered outliers if latencies were less than $500 \mathrm{msec}(6.5 \%$ of the trials for both words and nonwords) or greater than $1,500 \mathrm{msec}(0.4 \%$ of the trials for words and $1.3 \%$ of the trials for nonwords). Timing outliers were replaced with the cutoff latency (i.e., 500 or 1,500 msec). 
Comparison. We used $t$ tests to compare naming latencies for high-frequency words and nonwords, as well as timing latencies produced after each type of naming trial. The means are presented in Table 1. Naming latencies for high-frequency words were shorter than naming latencies for nonwords $\left[t_{\mathrm{S}}(52)=8.53, p<.001 ; t_{\mathrm{I}}(58)=\right.$ $9.39, p<.001]$. The difference between timing latencies following high-frequency words versus nonwords was also significant $\left[t_{\mathrm{S}}(52)=2.94, p<.01 ; t_{\mathrm{I}}(58)=3.16\right.$, $p<.01]$. The correlation between mean naming latency and mean timing latency for all the items was also significant $[r(60)=+.58 ; t(58)=5.42, p<.001$, one-tailed $]$, as was the correlation for nonwords alone $[r(30)=+.64$; $t(28)=4.41, p<.001$, one-tailed], but not for words alone $[r(30)=+.06 ; t(28)=0.32$, n.s. $]$.

\section{Discussion}

As expected, naming latencies for high-frequency words were significantly shorter than naming latencies for nonwords. More importantly, this difference carried over, as indicated by the significantly shorter timing durations following words than following nonwords and the significant positive correlation between naming latencies and subsequent timing latencies. This timing difference occurring after easy versus difficult stimuli supports the idea that the difficulty of naming an item influences time perception and that whatever changes in time perception arise during a naming trial last at least $3 \mathrm{sec}$. Thus, these results suggest that a time perception account of sequential effects is to be preferred to an account based on trialby-trial alterations in the position of the time criterion.

Although the results of Experiment 1 provide evidence that time perception is influenced by the difficulty of the stimulus being named and that the effect lasts at least $3 \mathrm{sec}$, one could argue that this effect may have been an artifact of using nonwords as the difficult stimuli. For example, the participants may have continued to think about whether their nonword pronunciation was correct, distracting them from the timing task. Indeed, the correlation between naming and timing latencies for words alone was not significant, although this was probably due to the severe restriction of range on naming latencies for high-frequency words. Experiment 2 involved an identical task alternation manipulation; however, only words (of varying difficulty) were used, in order to examine this possible alternative explanation. Because sequential effects in naming are typically small $(8-17 \mathrm{msec})$, it was necessary to produce a large range of word-naming times. As such, the selected words varied dramatically on both frequency and length.

\section{EXPERIMENT 2}

\section{Method}

Participants. Forty-seven undergraduate students received course credit in an introductory psychology course for their participation in this experiment. The participants reported having normal or correctedto-normal vision and being native speakers of English. Seven of these participants were not included in the analysis because their combined mechanical and naming error rate was greater than $30 \%$.

Stimuli, Apparatus, and Procedure. The stimuli consisted of 84 words, ranging from 3 to 14 letters in length and from 0 to 451,298 in frequency (HAL norms from elexicon database, Balota et al., 2002; stimuli available at psychonomic.org/archive; see archived materials for Taylor \& Lupker, 2006). Items were selected so that a wide range of naming times would be produced. To aid this process, the elexicon.wustl.edu Web site (Balota et al., 2002) was consulted. All other aspects of the procedure and apparatus were the same as those in Experiment 1.

\section{Results}

Data trimming. Trials in which the naming response was incorrect were eliminated from the latency analyses ( $10.0 \%$ of the trials). A trial was considered an outlier and omitted from the latency analyses if the naming latency was less than $150 \mathrm{msec}$ or greater than $2,000 \mathrm{msec}$ (no trials had latencies less than $150 \mathrm{msec}$; on $2.6 \%$ of the trials, latencies were greater than $2,000 \mathrm{msec}$ ). Timing trials were considered outliers if latencies were less than $500 \mathrm{msec}(2.1 \%$ of the trials) or greater than $1,500 \mathrm{msec}$ ( $2.7 \%$ of the trials). Timing outliers were replaced with the cutoff latency (i.e., 500 or $1,500 \mathrm{msec}$ ).

In addition, error rates for individual items were examined, and any item for which more than $30 \%$ of the trials were errors (including microphone and pronunciation errors) were removed from the analysis. Eleven items were removed (contaminate, electrocution, premeditation, indoctrination, preservative, extenuating, resuscitate, wherewithal, companionable, senility, and intransitive).

Comparison. A correlation was perfvormed to determine whether naming latency was related to the duration of the produced interval. The correlation between mean naming latency and mean timing latency was significant $[r(73)=+.27 ; t(71)=2.36, p<.05$, one-tailed $]$.

\section{Discussion}

Consistent with the results of Experiment 1, word naming latencies in Experiment 2 were significantly related to timing durations. This relationship between naming latency and timing duration supports the idea that the difficulty of naming an item influences time perception and that whatever changes in time perception arise during a

Table 1

Mean Latencies (RTs, in Milliseconds) As a Function of Condition and Stimulus Type in Experiment 1

\begin{tabular}{|c|c|c|c|c|c|c|c|}
\hline \multirow[b]{3}{*}{ Stimulus Type } & \multicolumn{3}{|c|}{ Naming } & \multicolumn{4}{|c|}{ Timing } \\
\hline & \multicolumn{2}{|c|}{ RT } & \multirow[b]{2}{*}{ ER } & \multicolumn{2}{|c|}{ RT } & \multirow[b]{2}{*}{ Too Fast } & \multirow[b]{2}{*}{ Too Slow } \\
\hline & $M$ & $S D$ & & $M$ & $S D$ & & \\
\hline High-frequency regular & 623 & 98.6 & $2.0 \%$ & 789 & 146.4 & $6.5 \%$ & $0.4 \%$ \\
\hline Nonwords & 722 & 168.4 & $8.2 \%$ & 806 & 158.4 & $6.5 \%$ & $1.3 \%$ \\
\hline
\end{tabular}

Note-ER, error rate. 
naming trial last at least $3 \mathrm{sec}$. As in Experiment 1, these results support a time perception account of Taylor and Lupker's (2001) sequential effects, while providing no support for their alternative explanation of sequential effects, that there are trial-by-trial alterations in the position of the time criterion.

\section{GENERAL DISCUSSION}

The results of the present experiments support the idea that the sequential effects observed by Taylor and Lupker (2001) were time perception effects. In fact, the size of the timing sequential effect observed in Experiment 1 is virtually identical to the size of the naming sequential effects in Taylor and Lupker's (2001) experiments.

The obvious next question is, what is the mechanism underlying these influences on time perception? The predominant explanation of stimulus difficulty effects on time perception is that they are due to attentional resource demands. In general, cognitive models of time perception include an internal clock (the exact location and nature of which are usually unspecified) that produces "ticks" at regular enough intervals that they can be used to monitor the passage of time reasonably accurately, a "counter" that registers these ticks, and some sort of memory mechanism to keep track of how many ticks occurred during a specified interval (as a standard for comparison). It is assumed that there is a strong positive correlation between the number of ticks counted and perceived duration (i.e., the more ticks counted, the longer the interval is perceived to be). It is also assumed that attention is required in order to accurately count ticks. When attention is allocated elsewhere (e.g., to word reading), the tendency is to miss ticks, and therefore, the elapsed time is underestimated. Thus, Warm and McCray (1969) explained their results by arguing that because longer/low-frequency words are harder to process than shorter/high-frequency words, participants could not devote as much attention to monitoring the passage of time when processing longer/low-frequency words. As a result, time appeared to pass more slowly when longer/ low-frequency words were processed.

The attention allocation account provides a perfectly adequate explanation for online effects of stimulus difficulty on time perception - that is, those effects that occur during that period of time in which both stimulus processing and timing operations are taking place. However, the attention allocation account does not predict carryover effects in time perception such as those observed here, because once stimulus processing is complete (e.g., after the word or nonword has been named), the allocation of attention will be controlled only by the processing of the subsequent stimulus (i.e., the asterisks; see Fortin et al., 1993).

Assuming the same general structures (i.e., an internal clock, a counter, and a memory mechanism), a second way in which processing difficulty could affect time perception would be through a change in the tick rate of the internal clock. Factors such as physiological arousal have been proposed to influence internal clock speed through such a mechanism (e.g., Block, 1990). To account for Warm and McCray's (1969) results, the argument would be that the more difficult processing was, the slower the tick rate would be. Again, as a result, time would appear to pass more slowly while more difficult stimuli were processed (i.e., fewer ticks would occur during the processing interval).

In contrast to the attention allocation account, the clock speed account might be able to explain sequential effects if it were the case that changes in tick rate carry over from one trial to another. As has been noted, changes in tick rate are typically proposed to be due to changes in physiological arousal. Researchers have attempted to manipulate physiological arousal (and thereby manipulate clock speed) in many ways, including presenting beeps before a stimulus to increase arousal (e.g., Wearden, Philpott, \& Win, 1999), increasing arousal by inducing stress (e.g., Ozel, Larue, \& Dosseville, 2004), and increasing emotional arousal (e.g., Droit-Volet, Brunot, \& Niedenthal, 2004). In all of these cases, changes in physiological arousal do appear to be relatively long-lasting. Thus, these changes in arousal could certainly last through a typical interstimulus interval, potentially explaining the trial-by-trial sequential effects observed by Taylor and Lupker (2001).

Note, however, that the typical effect of physiological arousal is in the opposite direction to that which would be expected from the nature of the sequential effects observed by Taylor and Lupker (2001). That is, in Taylor and Lupker's (2001) experiments, participants responded more slowly to an item preceded by a difficult item. This result could be explained only as an effect of physiological arousal if it could be assumed that difficult items cause the internal clock to slow down. Logically, however, difficult stimuli would seem to be more arousing than easy stimuli. Thus, if anything, difficult stimuli should increase physiological arousal and clock speed, rather than decreasing it.

At present, then, it does not appear that either an attention allocation account or a clock speed account, as currently conceived, could provide an explanation of Taylor and Lupker's (2001) results. Although it is possible that either account could be modified to explain those results, the clock speed account would seem to have slightly more potential. Two issues would need to be addressed. First, there must be a mechanism that allows the speed of the clock to shift somewhat rapidly. Second, and more importantly, this shifting mechanism must work in the way required by the data. That is, the mechanism must slow down the clock as a result of difficult processing, rather than speed it up.

The situation is even less promising for attention allocation accounts. To explain carryover effects in time perception, an attention allocation account must provide some means by which stimulus difficulty effects on time perception remain after processing is complete. Although current attention allocation accounts do not appear to allow for this possibility (e.g., Fortin et al., 1993), there are results from a number of other paradigms suggesting that longer lasting changes in attention allocation do occur. For example, Tipper, Grison, and Kessler (2003) showed evidence that attention was less likely to be allocated to a previously seen stimulus that was ignored (inhibition of return), an effect which lasted for at least $3 \mathrm{~min}$. Thus, it is 
not impossible that there would be a mechanism that could produce long-term effects on attention allocation, leading to carryover effects in time perception.

The present data, coupled with Taylor and Lupker's (2006) results, provide strong evidence that time perception processes play an important role in speeded-response tasks. However, one should note that sequential effects, the focus of the present investigation, are relatively small effects. Furthermore, in a stimulus block containing varied stimuli, stimulus randomization would mean that sequential effects probably will not affect the various stimulus conditions differentially. Thus, in a practical sense, the impact of these effects on the means of the various conditions in a mixed block will be quite small. In contrast, the impact of sequential effects on latencies in pure blocks of easy and hard stimuli may be more noticeable, due to the fact that each stimulus in a pure block of easy stimuli will benefit from having an easy stimulus preceding it (and vice versa). Nonetheless, from the perspective of the time criterion account, what is probably more important in terms of affecting mean latencies are the changes in criterion position, from trial block to trial block, as a function of the difficulty of the stimuli in that block.

In summary, the present results demonstrate that the difficulty of stimulus processing affects time perception after the stimulus has disappeared. This fact, together with the principles outlined in Lupker et al.'s (1997) time criterion account, is consistent with the notion that the sequential effects in naming reported by Taylor and Lupker (2001) are the result of carryover effects of stimulus difficulty on time perception and are not due to trial-by-trial shifts in the position of the time criterion. In addition, because the currently held ideas about how time perception is affected by stimulus difficulty - the attention allocation and clock speed accounts - cannot explain carryover effects in time perception, the present research also suggests that researchers should consider ways to expand time perception theories.

\section{AUTHOR NOTE}

This research was based on a dissertation presented by the first author in partial fulfillment of the requirements for a Ph.D. at the University of Western Ontario. This work was partially supported by Natural Sciences and Engineering Research Council of Canada Grant A6333 to the second author. We thank John Wearden, Mike Cortese, and an anonymous reviewer for their comments on an earlier draft of the manuscript. Correspondence concerning this article should be addressed to S. J. Lupker, Department of Psychology, University of Western Ontario, London, ON, N6A 5C2 Canada (e-mail: lupker@uwo.ca).

\section{REFERENCES}

Balota, D. A., Cortese, M. J., Hutchison, K. A., Neely, J. H., Nelson, D., Simpson, G. B., \& Treiman, R. (2002). The English Lexicon Project: A Web-based repository of descriptive and behavioral measures for 40,481 English words and nonwords. St. Louis, MO: Washington University. Available at elexicon.wustl.edu/.

BLOCK, R. A. (1990). Models of psychological time. In R. A. Block (Ed.), Cognitive models of psychological time (pp. 1-35). Hillsdale, NJ: Erlbaum

Brown, S. W. (1985). Time perception and attention: The effects of prospective versus retrospective paradigms and task demands on perceived duration. Perception \& Psychophysics, 38, 115-124.

Brown, S. W., StubBs, D. A., \& WeSt, A. N. (1992). Attention, multiple timing, and psychophysical scaling of temporal judgments. In F. Macar, V. Pouthas, \& W. J. Friedman (Eds.), Time, action, and cognition: Towards bridging the gap (pp. 129-140). Dordrecht: Kluwer.

CASINI, L., \& MACAR, F. (1997). Effects of attention manipulation on judgments of duration and of intensity in the visual modality. Memory \& Cognition, 25, 812-818.

Chastain, G., \& Ferraro, F. R. (1997). Duration ratings as an index of processing resources required for cognitive tasks. Journal of General Psychology, 124, 49-76.

Chateau, D., \& Lupker, S. J. (2003). Strategic effects in word naming: Examining the route-emphasis versus time-criterion accounts. Journal of Experimental Psychology: Human Perception \& Performance, 29, 139-151.

Coltheart, M., Rastle, K., Perry, C., Langdon, R., \& Ziegler, J. (2001). DRC: A dual route cascaded model of visual word recognition and reading aloud. Psychological Review, 108, 204-256.

Droit-Volet, S., Brunot, S., \& Niedenthal, P. M. (2004). Perception of the duration of emotional events. Cognition \& Emotion, 18, 849-858.

Fortin, C., Rousseau, R., Bourque, P., \& Kirouac, E. (1993). Time estimation and concurrent nontemporal processing: Specific interference from short-term-memory demands. Perception \& Psychophysics, 53, 536-548.

Hicks, R. E., Miller, G. W., \& Kinsbourne, M. (1976). Prospective and retrospective judgements of time as a function of amount of information processed. American Journal of Psychology, 89, 719-730.

Hochhaus, L., Swanson, L. G., \& Carter, A. L. (1991). Common words are longer in apparent duration than are rare words. Journal of General Psychology, 118, 83-95.

Kinoshita, S., \& LUPKER, S. J. (2002). Effects of filler type in naming: Change in time criterion or attentional control of pathways? Memory \& Cognition, 30, 1277-1287.

Kinoshita, S., \& LuPKer, S. J. (2003). Priming and attentional control of lexical and sublexical pathways in naming: A reevaluation. Journal of Experimental Psychology: Learning, Memory, \& Cognition, 29, 405-415.

Lupker, S. J., Brown, P., \& Colombo, L. (1997). Strategic control in a naming task: Changing routes or changing deadlines? Journal of Experimental Psychology: Learning, Memory, \& Cognition, 23, 570-590.

McClain, L. (1983). Interval estimation: Effect of processing demands on prospective and retrospective reports. Perception \& Psychophysics, 34, 185-189.

Monsell, S., Patterson, K. E., Graham, A., Hughes, C. H., \& MiLroy, R. (1992). Lexical and sublexical translation of spelling to sound: Strategic anticipation of lexical status. Journal of Experimental Psychology: Learning, Memory, \& Cognition, 18, 452-467.

Ozel, S., Larue, J., \& Dosseville, F. (2004). Effect of arousal on internal clock speed in real action and mental imagery. Canadian Journal of Experimental Psychology, 58, 196-205.

TAYLOR, T. E., \& LUPKER, S. J. (2001). Sequential effects in naming: A time-criterion account. Journal of Experimental Psychology: Learning, Memory, \& Cognition, 27, 117-138.

TAYLOR, T. E., \& LUPKER, S. J. (2006). Time perception and word recognition: An elaboration of the time-criterion account. Perception \& Psychophysics, 68, 933-945.

Thomas, E. A. C., \& Weaver, W. B. (1975). Cognitive processing and time perception. Perception \& Psychophysics, 17, 363-367.

Tipper, S. P., Grison, S., \& KessLer, K. (2003). Long-term inhibition of return of attention. Psychological Science, 14, 19-25.

Warm, J. S., \& MCCray, R. E. (1969). Influence of word frequency and length on the apparent duration of tachistoscopic presentations. Journal of Experimental Psychology, 79, 56-58.

Wearden, J. H., Philpott, K., \& Win, T. (1999). Speeding up and (...relatively...) slowing down an internal clock in humans. Behavioural Processes, 46, 63-73.

Zevin, J. D., \& Balota, D. A. (2000). Priming and attentional control of lexical and sublexical pathways during naming. Journal of Experimental Psychology: Learning, Memory, \& Cognition, 26, 121-135.

(Manuscript received November 28, 2005; revision accepted for publication May 26, 2006.) 